\title{
The dangers of herbalism
}

\author{
P D L Maurice, J J Cream
}

\section{Department of}

Dermatology, Charing

Cross Hospital, London W6 8RF

P D L Maurice, MD, senior registrar

J J Cream, FRCP, consultant

Correspondence to: Dr Maurice.

BrMed $\mathcal{F}$ 1989;299:1204
Herbal preparations are often ignored when a drug history is taken, but because of the biological potency of many of these preparations and their increasing availability and popularity patients should be asked specifically about their use, especially when presenting with unusual symptoms or signs.

\section{Case report}

A 30 year old man of Indian extraction presented at a dermatology clinic with a six month history of photosensitivity. After being exposed to summer sunshine in London in the middle of the day he would develop erythema and itching of the hands and ears the same evening and blistering the following day. He had had extensive vitiligo for 20 years, but the photosensitivity also affected normally pigmented skin. He denied having a history of photosensitivity and said that he was not taking any drugs. He had slight postinflammatory hyperpigmentation at the site of a recent blister and vitiligo but no milia or scarring. Because he drank a moderate amount of alcohol we measured the urinary porphyrin concentration to exclude porphyria cutanea tarda, but this yielded negative results. Tests for antinuclear antibody yielded weakly positive results.

He then told us that during the previous six months he had been taking a herbal infusion as a self treatment for vitiligo. This had not had much effect on the depigmentation but seemed to be related to his photo- sensitivity. We advised him to stop taking the infusion and three months later he had had no problems with photosensitivity until the week before, when he had taken the infusion again and sat out in the sun, whereupon the blistering had recurred.

\section{Comment}

Our patient took an infusion prepared from the powdered seeds of Psoralea corylifolia in a daily dose equivalent to $30 \mathrm{~g}$ of the seeds. $P$ corylifolia is a leguminous plant native to India (where it is known as babchi) that has been used since $1400 \mathrm{BC}$ to treat vitiligo and psoriasis by ingestion of the powdered seeds and by externally applying - an oleoresinous extract of the seeds. ${ }^{1}$ The seed contains psoralen, isopsoralen, and psoralidin. ${ }^{2} P$ corylifolia contains more than 10 times the amount of psoralen per unit weight of dried seeds than any other members of the genus, and an extract of the seeds has potent photosensitising activity when applied to the skin of guinea pigs. ${ }^{3}$ Patients with leucoderma have been treated at the Central Drug Research Institute and at Vellore Medical College, India, with a mixture of psoralen and isopsoralen prepared from the seeds of $P$ corylifolia, and a useful therapeutic effect was reported in young patients with disease of recent onset. ${ }^{1}$

1 Mukerii B. Psoralea and other indigenous drugs used in leucoderma. Fournal of Science and Industrial Research 1956;15 A: 1-12.

2 Pathak MA, Daniels F, Fitzpatrick TB. The presently known distribution of furocoumarins (psoralens) in plants. F Invest Dermatol 1962;39:225-39.

3 Innocenti G, Dall'Acqua F, Guiotto A, Caporale G. Investigation of skinphotosensitizing activity of various kinds of Psoralea. Planta Med 1977;31: $151-5$

(Accepted 24 August 1989)

energy expenditure of $3.6 \mathrm{MJ}$. This programme enhanced exercise tolerance and modified favourably the metabolic and cardiovascular responses to standard, submaximal exercise.

Cholesterol concentration was assayed by an enzymatic colorimetric method (Boehringer Mannheim). Multivariate analysis of trends did not show any significant difference between the walkers and the controls in the total cholesterol concentration during the study. There was a significant trend in high density lipoprotein cholesterol concentration in the walkers over time, which was adequately modelled by a straight line. The overall difference between the lines for the walkers and controls was attributable to a difference in the slopes $(p<0.0001)$, estimated as being $0.02 \mathrm{mmol} / \mathrm{l} /$ month $(95 \%$ confidence interval 0.01 to $0.03 \mathrm{mmol} / \mathrm{l} /$ month) over the 12 months (table). There were no

Mean (SEM) plasma cholesterol concentrations and average daily intakes of energy and fat in 28 women during programme of brisk walking and in 16 controls over 12 months

Department of Human

Sciences, Loughborough

University

P R M Jones, PHD, professor

N G Norgan, PHD, senior

lecturer

Correspondence to: Dr Hardman.

BrMed f 1989;299:1204-5
In England and Wales coronary heart disease is esponsible for $23 \%$ of deaths in women under 75 , bu few studies have examined the potential of changes in ifestyle to influence risk factors for coronary heart lipoprotein cholesterol concentrations in formerly sedentary women.

\section{Subjects, methods, and results}

Forty four women volunteered for the study, of whom 28 joined the group allocated to brisk walking ("the walkers"; mean age 44.9 (SD 7.9) years) and 16 agreed to serve as controls (mean age $44 \cdot 4(9 \cdot 2)$ years). After baseline tests the controls maintained their habitual lifestyle and the walkers followed a progressive programme of brisk walking. Mean brisk walking pace was $1.72(0.26) \mathrm{m} / \mathrm{s}$ at the start of the study, increasing to $1.87(0.37) \mathrm{m} / \mathrm{s}$ after 12 months, and elicited $60 \%$ of predicted maximal oxygen uptake. The walkers walked for an average of 155 (48) minutes (range 75-287) per week over the year, which was equivalent to $16 \cdot 1-17 \cdot 4 \mathrm{~km}$ and an estimated weekly

\begin{tabular}{|c|c|c|c|c|}
\hline & Baseline & 3 Months & 6 Months & 12 Months \\
\hline \multicolumn{5}{|c|}{ Total cholesterol $(\mathrm{mmol} / \mathrm{l})$ : } \\
\hline Walkers & $5.35(0.23)$ & $5 \cdot 18(0 \cdot 20)$ & $5 \cdot 28(0 \cdot 18)$ & $5.00(0 \cdot 22)$ \\
\hline Controls & $5.41(0.26)$ & $5 \cdot 41$ & & $5 \cdot 29(0.24)$ \\
\hline \multicolumn{5}{|c|}{ HDL cholesterol $(\mathrm{mmol} / \mathrm{l})$ : } \\
\hline Walkers & $1 \cdot 17(0.08)$ & $1 \cdot 40(0.06)$ & $1.42(0.06)$ & $1.49(0.06)^{\star}$ \\
\hline Controls & $1.32(0.07)$ & $1.35(0.06)$ & $1 \cdot 33$ & $1.35(0.05)$ \\
\hline \multicolumn{5}{|c|}{ Total: HDL cholesterol: } \\
\hline Walkers & $5 \cdot 2(0 \cdot 4)$ & $3 \cdot 8($ & 3.9 & $3 \cdot 5(0 \cdot 2)^{\star}$ \\
\hline Controls & $4 \cdot 2(0 \cdot 2)$ & 3.9 & 2) & $4.4(0.3)$ \\
\hline \multicolumn{5}{|c|}{ Energy intake $(\mathrm{MJ})$ : } \\
\hline Walkers & $7 \cdot 7(0 \cdot 4)$ & & •4) & $7 \cdot 4(0 \cdot 4)$ \\
\hline Contro & $6 \cdot 9(0 \cdot 3)$ & & $7 \cdot 0(0 \cdot 3)$ & $7 \cdot 0(0 \cdot 3)$ \\
\hline \multicolumn{5}{|c|}{ Fat intake (g): } \\
\hline Walkers & $72(4)$ & & $69(4)$ & $69(4)$ \\
\hline Controls & $66(5)$ & & $67(4)$ & $67(4)$ \\
\hline
\end{tabular}

* Significant difference in trend over 12 months between walkers and controls. 